\title{
Geographical Variations and Factors Associated with Childhood Diarrhea in Tanzania: A National Population Based Survey 2015-16
}

\author{
Paul Edwin ${ }^{*}$, Muluken Azage ${ }^{2}$
}

OPEN ACCESS

Citation: Paul Edwin, Muluken Azage. Geographical Variations and Factors Associated with Childhood Diarrhea in Tanzania: A National Population Based Survey 2015-16. Ethiop J Health Sci.2017; 29(4):513.doi:http://dx.doi.org/ 10.4314/ejhs.v29i4.13

Received: March 25, 2019

Accepted: May 17, 2019

Published: July 1, 2019

Copyright: (C) 2019 Paul E., et al . This is an open access article distributed under the terms of the Creative Commons Attribution License, which permits unrestricted use, distribution, and reproduction in any medium, provided the original author and source are credited. Funding: Nil

Competing Interests: The authors declare that this manuscript was approved by all authors in its form and that no competing interest exists.

Affiliation and Correspondence:

${ }^{1}$ University of Dodoma, Department of

Statistics, United Republic of Tanzania

${ }^{2}$ Bahir Dar university - Public health,

College of Medicine and Health

Sciences, Bahir Dar university, Bahir

Dar, Ethiopia

*Email: edwinpaultuzo@gmail.com

\section{ABSTRACT}

BACKGROUND: Diarrhea remains the leading cause of morbidity and mortality among under 5 children in low-and middle-income countries. In Tanzania, diarrhea remains one of the major public health problems. This study aimed to investigate spatial variations and the factors correlated with diarrhea in under five children.

METHODS: This is a secondary data analysis using data from the population-based cross section Tanzanian Demographic and Health Survey 2015-16 data. Spatial analysis was done using the Bernoulli model from SaTScan ${ }^{\mathrm{TM}}$ software, and a generalized linear mixed model was used to identify the factors associated with childhood diarrhea.

RESULTS: The overall reported prevalence of childhood diarrhea for the under five children in Tanzania was $12.1 \%$ (95\% CI 11.3\%12.9\%). The SaTScan spatial statics analysis revealed that diarrhea in children was not random. The odds of diarrhea were 7.35 times higher $(A O R=7.35 ; 95 \%$ CI: 5.29, 10.22) among children in the 611 months age group compared to children within the 48-59 months of age. As mother's age increased, the risk of diarrhea for the under five children decreased whereas the highest risk of diarrhea was observed in the two rich income brackets richer $(A O R=1.70,95 \% C I=1.30,2.22)$, and richest $(A O R=1.05$, 95\%CI=1, 1.09). The odds of diarrhea were 1.25 times higher $(A O R=1.25,95 \% C I=1.06,1.46)$ among children with unsafe stool disposal compared to those with safe disposal.

CONCLUSION: The socio-demographic factors associated with diarrhea among children were mother's age in years, current age of the child, wealth index and child stool disposal.

KEYWORDS: Diarrhea, Children, Generalized Mixed Model, Tanzania

\section{INTRODUCTION}

Diarrhea is one of the major causes of morbidity and mortality among children of under five years of age worldwide, particularly in developing countries. It is responsible for 525,000 deaths (1), and 1.7 billion cases (2) among under 5 children each year. Most deaths from diarrhea occur among children of less than 2 years of age living in South Asia and sub-Saharan Africa (3). 
Even though diarrhea related deaths in children have declined significantly worldwide due to socioeconomic development and implementation of child survival interventions, the morbidity of childhood diarrhea in developing countries has not decreased significantly. In developing countries, a child experiences three or more episodes of diarrheal disease per year (4).

In Tanzania, community-based studies and facility-based reports revealed that diarrhea remains one of the public health problems. Health facility reports indicated that diarrhea was one of the top five causes of morbidity in outpatient visitors and mortality among under five children (5). Children are reported to suffer approximately 5 episodes of diarrhea per year (6). Community based studies in different parts of Tanzania reported that the prevalence of diarrhea is in the range of $6 \%(7)$ to $33 \%(8,9)$. The recent population based survey in $2015 / 16$ also found that the prevalence of diarrhea was $12 \%(10)$.

Previous studies have focused on the prevalence of diarrhea $(8,9)$, characteristics of individual's affected and identified factors associated with diarrhea using standard logistic regression, which ignores clustering effects (7). Observations within a cluster tend to be more alike than observations from different clusters and ordinary analyses that ignore this may be inappropriate (11). Ignoring clustering in analyses may overstate the precision of results; risk factors may be incorrectly stated as significant $(12,13)$. Thus, this analysis has been conducted to identify the factors that are associated with diarrhea using a generalized linear mixed model (GLMM). The GLMM considers the correlation between responses of interest for respondents from within the same cluster (14).

Different spatial statistical analyses have been increasingly applied in epidemiology to assess disease patterns, trends and relationships between health events and determinants $(15,16)$. The analysis of the spatial distribution of infectious diseases can provide information for policy-makers to target the use of scarce resources for public health interventions in a more targeted manner $(15,16)$. These results may be useful in identifying factors for future interventions to further reduce the prevalence of diarrhea in
Tanzania. Therefore, the aim of this study was to investigate the geographical variation and determinants of childhood diarrhea among under five children in Tanzania using a recent national population-based survey from 2015-16.

\section{METHODS}

Study design and sample size determination: This is a secondary data analysis study using the Tanzania Demographic and Health Survey 201516 (TDHS) dataset. The survey was designed to produce representative estimates for the main demographic and health indictors for the country as a whole. The survey involves data from Tanzania Mainland and Zanzibar, Dar es Salaam city, as well as other urban areas, and for all rural areas. The areas were grouped into nine geographical zones by stratified multistage cluster sampling. The sampling frame used for the 201516 TDHS is the Tanzania Population and Housing Census (TPHC), which was conducted in Tanzania in 2012. The sampling frame is a complete list of 608 enumeration areas (EAs) covering the country, provided by the National Bureau of Statistics (NBS) of Tanzania, the implementing agency for the 2015-16 TDHS. According to TDHS manual, "A census Enumeration Area (EA) is a geographical statistical unit created for a census and containing a certain number of households. An EA is usually a city block in urban areas and a village, a part of a village or a group of small villages in rural areas with its location and boundaries well defined and recorded on census maps" (17). According to TPHC 2012, sampling frame for enumeration areas to represent the country was designed and drawn from 25 regions of Tanzania Mainland, which were grouped further into 8 geographical zones, and from Zanzibar which has 5 regions and treated as one zone (Figure 1). Of the $608 \mathrm{EAs}$, 180 EAs were from urban areas and 428 EAs were from rural areas (Figure 2). With a fixed number of 22 households to be selected per EAs, the total number of households to be selected was 13,376; among them; 3,960 households were from urban areas, and 9,416 households were from rural areas. Of the total households to be selected, 12,563 were successfully interviewed. A total of 8,978 children aged under five years were included in

DOI: http://dx.doi.org/10.4314/ejhs.v29i4.13 
this analysis and the remaining were excluded due to absence of data on diarrhea statuses. The detailed methodology for sample selection and data collection is described in the Monitoring and Evaluation to Assess and Use Results of Demographic and Health Surveys (MEASURE
DHS) website (17), and the country specific methodology for the Tanzania TDHS 2015/16 is elaborated in the final report (in English) which can be freely downloaded from the MEASURE DHS website(10).

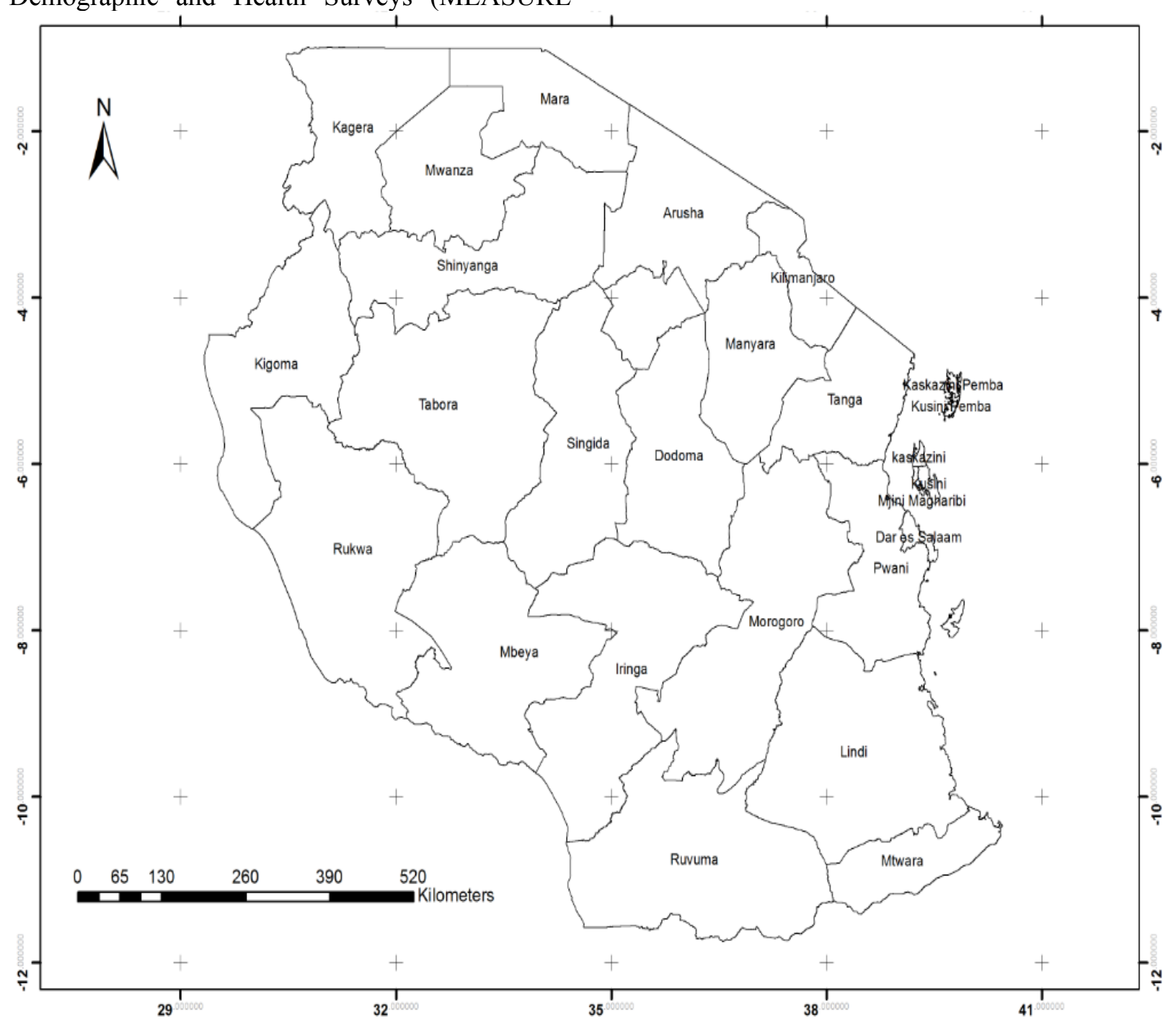

Figure 1: Location map of Tanzania

DOI: http://dx.doi.org/10.4314/ejhs.v29i4.13 


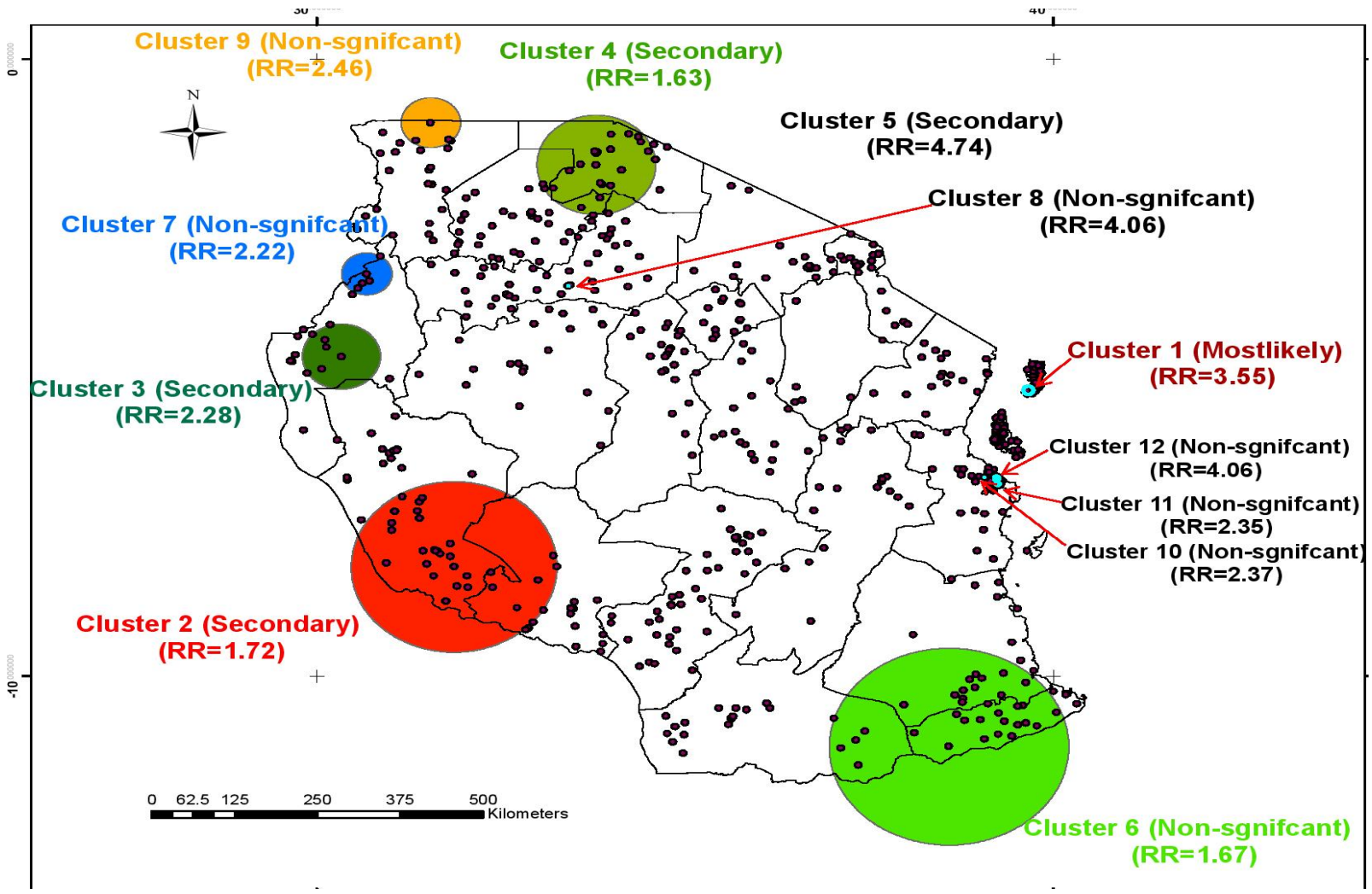

Figure 2: Pure Spatial Clusters of Child Diarrhea, DHS 2015/16, Tanzania

Outcome and exposure variables: The outcome variable from the TDHS 2015/16 used for this study was prevalence of diarrhea in children under 5 years of age during the two weeks prior to interview. Diarrhea was measured using the definition of a child having loose stools more frequently than usual in the two-week period preceding the survey (10).

The exposure variables include the information regarding the socio-demographic and economic characteristics of children of less than 5 years of age was obtained from interviews with their mothers/caregivers. Children's nutritional status was calculated according to the WHOMGRS 2006 Child Growth Standards. A z-score of height for age index (HAZ) $<-2 \mathrm{SD}$ was defined as stunted. A HAZ between-2SD and 3SD was considered as moderate stunting, and $\mathrm{HAZ}<-3 \mathrm{SD}$ as severe stunting.

Data analysis: Data analysis was done by using Stata V12. The chi square $(\chi 2)$ test was adopted to find associations between diarrhea status and categorical explanatory variables. In many regression analyses, observations sometimes show clustering, in which observations within clustersalmost $95 \%$ - tend to be correlated to each other. In this study, the sampling unit was the household, whereas all the eligible children in the selected households were sampled resulting in clusters of household members who were likely to have related background characteristics since some of the children may belong to the same mother or household. Therefore, for clustered binary outcome variable like this, a generalized liner mixed model with logistic link becomes an appropriate model to account for correlation among the subjects within a cluster (18). Sampling weight as provided by TDHS data was also used during analysis.

The SaTScan spatial statics analysis was also used to identify clusters of childhood diarrhea. SaTScan software creates a circular window that scans systematically throughout the study area to identify significant clustering of childhood diarrhea. The numbers of children with diarrhea and without diarrhea in each cluster follow Bernoulli distribution (19). In such type of data, the analysis was done using Bernoulli model from 
SaTScan $^{\mathrm{TM}}$ software version 9.3 which requires the number of children with diarrhea (as cases) and without diarrhea (as controls).

\section{RESULTS}

Prevalence of childhood diarrhea with geographical variation: Data of incidents of diarrhea in children under 5 years of age were collected from 8,978 mothers/caregivers in
Tanzania. The prevalence of diarrhea was $12.1 \%$ (95\%CI $11.3 \%-12.9 \%)$. There was a significant variation in prevalence of childhood diarrhea between different regions and places of residence. The highest prevalence of childhood diarrhea was found in Kigoma $(21.5 \%)$ while the lowest was recorded in Tabora $(5.1 \%)$. Higher prevalence of childhood diarrhea occurred in urban areas compared to rural areas (Table 1).

Table 1: Prevalence of Child Diarrhea by Region and Place of Residence, DHS 2016, Tanzania

\begin{tabular}{|c|c|c|c|c|c|}
\hline \multicolumn{4}{|c|}{ Child diarrhea status } & \multirow{2}{*}{$\begin{array}{c}\text { Lower } \\
\text { confidence } \\
\text { interval }\end{array}$} & \multirow{2}{*}{$\begin{array}{c}\text { Upper } \\
\text { confidence } \\
\text { interval }\end{array}$} \\
\hline Region & Yes & No & Prevalence & & \\
\hline Dodoma & 20 & 207 & 9.3 & 6.0 & 14.2 \\
\hline Lindi & 23 & 250 & 14.0 & 9.7 & 19.8 \\
\hline Mtwara & 15 & 144 & 17.8 & 12.6 & 24.5 \\
\hline Ruvuma & 19 & 243 & 12.1 & 8.3 & 17.3 \\
\hline Iringa & 22 & 196 & 8.0 & 5.0 & 12.5 \\
\hline Mbeya & 20 & 186 & 13.9 & 9.6 & 19.6 \\
\hline Singida & 57 & 290 & 8.3 & 5.7 & 11.8 \\
\hline Tabora & 29 & 162 & 5.1 & 3.5 & 7.5 \\
\hline Rukwa & 29 & 127 & 19.7 & 15.8 & 24.2 \\
\hline Kigoma & 27 & 211 & 21.5 & 17.1 & 26.7 \\
\hline Shinyanga & 18 & 188 & 12.0 & 9.0 & 15.8 \\
\hline Kagera & 29 & 185 & 10.9 & 7.9 & 14.8 \\
\hline Mwanza & 29 & 290 & 11.8 & 8.7 & 15.7 \\
\hline Mara & 25 & 445 & 17.3 & 13.9 & 21.3 \\
\hline Manyara & 74 & 291 & 11.7 & 8.3 & 16.2 \\
\hline Njombe & 76 & 308 & 10.0 & 6.5 & 15.0 \\
\hline Katavi & 45 & 368 & 14.0 & 11.0 & 17.7 \\
\hline Simiyu & 37 & 295 & 13.7 & 10.5 & 17.8 \\
\hline Geita & 42 & 305 & 9.4 & 7.0 & 12.6 \\
\hline \multicolumn{6}{|l|}{ Place of residence } \\
\hline Urban & 309 & 1745 & 14.9 & 13.2 & 16.7 \\
\hline Rural & 762 & 6162 & 11.1 & 10.3 & 12.1 \\
\hline Total & 1071 & 7907 & 12.1 & 11.3 & 12.9 \\
\hline
\end{tabular}

Spatial variation of childhood diarrhea: The SaTScan spatial statics analysis found that diarrhea in children was not random in Tanzania. Twelve clusters were identified with more observed cases than expected cases. However, only four clusters were significantly varied. The mostly likely cluster/primary cluster was comprised of five enumeration areas located at$5.36713 \mathrm{~N}, 39.66134 \mathrm{E}$ with a radius of $7.56 \mathrm{~km}$. The log likelihood ratio and relative risk of the most likely cluster were 35.891 ( $\mathrm{p}$-value $<0.001$ ) and 3.55 respectively. The remaining three significant clusters were secondary clusters and the other eight clusters were non-significant clusters (Figure 2 above).

Childhood diarrhea and socio-economic and demographic characteristics: From 8,978 sampled children, $1,087(12.1 \%)$ were reported to have diarrhea in the two weeks previous to the study interview. Among the 1,087 children having diarrhea, although not statistically significant $\mathrm{t}(p=0.188) \mathrm{t}$ he highest prevalence was noted in those children whose mothers had secondary or higher education (15.3\%), followed by those whose mothers had primary education $(12.3 \%)$ and those with no education (9.4\%) (Table 2). In 
Table 2: Socio-demographic characteristics of mothers, parents and children under five years of age, DHS 2016, Tanzania

\begin{tabular}{|c|c|c|}
\hline Variables & Frequency (\%) & Chi-square P-Value \\
\hline \multicolumn{3}{|l|}{ Mothers education level } \\
\hline No education & $214(9.36)$ & \\
\hline Primary & $652(12.34)$ & \\
\hline Secondary/Higher & $205(15.25)$ & 0.19 \\
\hline \multicolumn{3}{|l|}{ Partner's education status } \\
\hline No education & $116(9.23)$ & \\
\hline Primary & $602(12.13)$ & \\
\hline Secondary/Higher & $172(12.67)$ & 0.18 \\
\hline \multicolumn{3}{|l|}{ Mother's age in years } \\
\hline $15-22$ & $283(16.87)$ & \\
\hline $23-30$ & $433(12.16)$ & \\
\hline $31-38$ & $257(10.03)$ & \\
\hline $39-49$ & $98(8.55)$ & $<0.0001$ \\
\hline \multicolumn{3}{|l|}{ Location of residence } \\
\hline Urban & $309(14.85)$ & \\
\hline Rural & $762(11.12)$ & $<0.0001$ \\
\hline \multicolumn{3}{|l|}{ Current age of children (years) } \\
\hline$<6$ & $62(6.29)$ & \\
\hline $6-11$ & $221(21.84)$ & \\
\hline $12-23$ & $413(21.07)$ & \\
\hline $24-35$ & $193(11.31)$ & \\
\hline $36-47$ & $123(7.24)$ & $<0.0001$ \\
\hline $48-59$ & $59(4.21)$ & \\
\hline \multicolumn{3}{|c|}{ Number of Children under five years } \\
\hline $0-1$ & $393(13.43)$ & \\
\hline 2 & $412(11.79)$ & \\
\hline$\geq 3$ & $266(10.81)$ & 0.03 \\
\hline \multicolumn{3}{|l|}{ Mother's Occupation } \\
\hline Not working & $190(13.07)$ & \\
\hline Working & $881(11.92)$ & 0.56 \\
\hline \multicolumn{3}{|l|}{ Wealth Index } \\
\hline Poorest & $202(9.23)$ & \\
\hline Poorer & $235(11.58)$ & \\
\hline Middle & $196(12.03)$ & \\
\hline Richer & $251(14.23)$ & \\
\hline Richest & $187(14.91)$ & $<0.0001$ \\
\hline \multicolumn{3}{|l|}{ Drinking water supply } \\
\hline Improved water & $608(12.55)$ & \\
\hline Unimproved water & $463(11.62)$ & 0.55 \\
\hline \multicolumn{3}{|l|}{ Sanitation facilities } \\
\hline Improved & $501(13.34)$ & \\
\hline Unimproved & $570(11.13)$ & 0.06 \\
\hline \multicolumn{3}{|l|}{ Child stool disposal } \\
\hline Safe & $653(12.87)$ & \\
\hline Unsafe & $418(11.02)$ & 0.04 \\
\hline \multicolumn{3}{|l|}{ A z-score of height for age } \\
\hline Severe stunting & $32(12.75)$ & \\
\hline Moderate stunting & $181(11.97)$ & \\
\hline Not stunted & $858(12.12)$ & 0.59 \\
\hline
\end{tabular}

DOI: http://dx.doi.org/10.4314/ejhs.v29i4.13 
terms of their partners, although it was also not significant $(P=0.180)$, the highest prevalence was among those with secondary or higher education $(12.7 \%)$ and primary education $(12.1 \%)$ and the lowest among those with no education (9.2\%). The study revealed that there was a significant relationship between diarrhea status of under five children with mother's age and residential setting $(\mathrm{P}<0.0001)$. The highest prevalence was observed in children with mothers aged $15-22$ years $(16.9 \%)$ whereas the lowest was found in children with mothers aged $39-49$ years $(8.6 \%)$. In the case of residential setting, most children with diarrhea were observed from urban settings with a prevalence of $14.9 \%$.

Table 2 also shows that the child's age $(\mathrm{P}<0.0001)$ and the number of under five children in the household $(\mathrm{P}=0.030)$ were also related to diarrhea status. The highest prevalence was observed in children aged 6-11months (21.8\%), closely followed by those aged 12-23 months $(21.1 \%)$, while the lowest prevalence was observed in children aged 48-59 months (4.2\%). The highest prevalence was noted in children from families with no or one under 5 child $(13.4 \%)$, while the lowest was recorded for families with three or more under five children $(10.8 \%)$.

Predictors of childhood diarrhea: The results of the bivariate and multivariable generalized linear mixed model (logistic link) (GLMM) are presented in Table 3. In this study, univariate analysis revealed that mother's occupation, drinking water supply, and a z-score of height for age were not statistically significant since $p>0.05$. Thus, these explanatory variables were removed from the final model. The final GLMM revealed that there was a statistically significant relationship between under five children's diarrhea status and mother's age in years, current children age, wealth index, and child stool disposal since $p<0.05$.

Table 3 depicts that although in the final model mothers' and partners' education were no longer significant $(p<0.05)$, diarrhea status was 1.19 times higher for mothers with primary education compared to those with no education. In the case of partners' education, likewise children's diarrhea status was the highest for the partners with primary education $(\mathrm{AOR}=1.09)$ and the lowest for those with secondary or higher education level $(\mathrm{AOR}=0.90)$ compared to those with no education. There was a statistically significant relationship of children diarrhea status with the mother's age in years. Controlling other factors in the model, as mother's age increased, the risk of diarrhea for the under five children decreased; children of women aged 23-30 years were at higher risk $(\mathrm{AOR}=0.74, \mathrm{CI}=0.61,0.90)$ compared to those aged 31-38 years $(\mathrm{AOR}=0.65$, $\mathrm{CI}=0.52,0.80)$ and $39-49$ years $(\mathrm{AOR}=0.54$, $\mathrm{CI}=0.40,0.72)$. In the case of residence location, the final model revealed that although it was not statistically significantly associated with under five children diarrhea controlling other variables in the model, the risk of diarrhea was higher in urban (reference category) compared to rural (AOR $=0.87, \mathrm{CI}=0.68,1.10)$ settings. The study also found that the risk of diarrhea was decreased from 6-11 months with increasing age of the child (in months) being highest at 6-11 months ( $\mathrm{AOR}=7.35, \mathrm{CI}=5.29,10.22)$ followed by those aged 12-23 months $(\mathrm{AOR}=6.20, \mathrm{CI}=4.56,8.42)$ compared to those children aged48-59 months.

Although preliminary bivariate analysis revealed that there was association between diarrhea and sanitation facilities used in the households ( $p=0.002)$ as well as the number of children of under five years $(p=<0.05)$, in the final model these variables were no longer statistically significant since $p>0.05$ (Table 3 ). There was a statistically significant relationship between under five children diarrhea and child stool disposal $(p=0.007)$. Households who used unsafe child stool disposal were at higher risk of diarrhea $(\mathrm{AOR}=1.25, \mathrm{CI}=1.06,1.46)$ compared to those who used safe stool disposal. The study also noted that, controlling for other explanatory variables in the final model, there was an association between diarrhea and household wealth. The highest risk was observed in the two rich income brackets, i.e. richer $(\mathrm{AOR}=1.70$, $\mathrm{CI}=1.30,2.22)$ and richest $(\mathrm{AOR}=1.59, \mathrm{CI}=1.12$, 2.27 ), followed by middle ( $\mathrm{AOR}=1.50, \mathrm{CI}=1.18$, 1.91) and lowest to the poorer (AOR $=1.41$, $\mathrm{CI}=1.12,1.78)$ brackets as compared to the lowest rates in the poorest income bracket, which has been used as the reference category.

DOI: http://dx.doi.org/10.4314/ejhs.v29i4.13 
Table 3: Generalized linear mixed model (logistic link) odds ratio and p-values for univariate and multivariable analysis for the factors associated with under five children diarrhea, DHS 2016, Tanzania

\begin{tabular}{|c|c|c|c|c|}
\hline Variable & COR $(95 \% \mathrm{CI})$ & P-Value & AOR (95\%CI) & P-Value \\
\hline \multicolumn{5}{|c|}{ Mothers education level } \\
\hline No education & $*$ & & & \\
\hline Primary & $1.36[1.15,1.62]$ & $<0.0001$ & $1.19[0.97,1.47]$ & 0.09 \\
\hline Secondary/Higher & $1.75[1.40,2.18]$ & $<0.0001$ & $1.09[0.80,1.48]$ & 0.60 \\
\hline \multicolumn{5}{|c|}{ Partner's education status } \\
\hline No education & $*$ & & & \\
\hline Primary & $1.36[1.08,1.70]$ & 0.008 & $1.09[0.85,1.39]$ & 0.50 \\
\hline Secondary/Higher & $1.43[1.10,1.88]$ & 0.009 & $0.90[0.65,1.23]$ & 0.51 \\
\hline \multicolumn{5}{|l|}{ Mother's age in years } \\
\hline $15-22$ & $*$ & & & \\
\hline $23-30$ & $0.68[0.58,0.80]$ & $<0.0001$ & $0.74[0.61,0.90]$ & 0.002 \\
\hline $31-38$ & $0.55[0.46,0.66]$ & $<0.0001$ & $0.65[0.52,0.80]$ & $<0.0001$ \\
\hline $39-49$ & $0.46[0.36,0.59]$ & $<0.0001$ & $0.54[0.40,0.72]$ & $<0.0001$ \\
\hline \multicolumn{5}{|l|}{ Location of residence } \\
\hline Urban & $*$ & & & \\
\hline Rural & $0.72[0.62,0.82]$ & $<0.0001$ & $0.87[0.68,1.10]$ & 0.24 \\
\hline \multicolumn{5}{|c|}{ Current age of children (months) } \\
\hline$<6$ & $1.52[1.06,2.19]$ & 0.022 & $1.45[0.97,2.20]$ & 0.07 \\
\hline $6-11$ & $6.41[4.80,8.57]$ & $<0.0001$ & $7.35[5.29,10.22]$ & $<0.0001$ \\
\hline $12-23$ & $6.10[4.67,7.98]$ & $<0.0001$ & $6.20[4.56,8.42]$ & $<0.0001$ \\
\hline $24-35$ & $2.89[2.17,3.86]$ & $<0.0001$ & $3.12[2.26,4.31]$ & $<0.0001$ \\
\hline $36-47$ & $1.78[1.30,2.42]$ & $<0.0001$ & $1.84[1.30,2.59]$ & 0.001 \\
\hline $48-59$ & $*$ & & & \\
\hline \multicolumn{5}{|c|}{ Number of Children under five years } \\
\hline $0-1$ & $*$ & & & \\
\hline 2 & $0.86[0.74,0.997]$ & 0.046 & $1.12[0.93,1.32]$ & 0.25 \\
\hline$>=3$ & $0.78[0.66,0.92]$ & 0.004 & $0.94[0.76,1.16]$ & 0.57 \\
\hline \multicolumn{5}{|l|}{ Mother's Occupation } \\
\hline Not working & * & & & \\
\hline Working & $0.90[0.76,1.07]$ & 0.242 & & \\
\hline \multicolumn{5}{|l|}{ Wealth Index } \\
\hline Poorest & $*$ & & & \\
\hline Poorer & $1.29[1.05,1.58]$ & 0.015 & $1.41[1.12,1.78]$ & 0.004 \\
\hline Middle & $1.35[1.09,1.65]$ & 0.005 & $1.50[1.18,1.91]$ & 0.001 \\
\hline Richer & $1.63[1.33,1.99]$ & $<0.0001$ & $1.70[1.30,2.22]$ & $<0.0001$ \\
\hline Richest & $1.72[1.40,2.12]$ & $<0.0001$ & $1.59[1.12,2.27]$ & 0.010 \\
\hline \multicolumn{5}{|c|}{ Drinking water supply } \\
\hline Improved water & $*$ & & & \\
\hline Unimproved water & $0.92[0.81,1.04]$ & 0.196 & & \\
\hline \multicolumn{5}{|l|}{ Sanitation facilities } \\
\hline Improved & $*$ & & & \\
\hline Unimproved & $0.81[0.71,0.92]$ & 0.002 & $0.94[0.79,1.12]$ & 0.50 \\
\hline \multicolumn{5}{|l|}{ Child stool disposal } \\
\hline Safe & $*$ & & & \\
\hline Unsafe & $0.84[0.73,0.96]$ & 0.009 & $1.25[1.06,1.46]$ & 0.007 \\
\hline \multicolumn{5}{|c|}{ A z-score of height for age } \\
\hline Severe stunting & $*$ & & & \\
\hline Moderate stunting & $0.94[0.61,1.44]$ & 0.77 & & \\
\hline Not stunted & $0.95[0.63,1.43]$ & 0.81 & & \\
\hline
\end{tabular}

DOI: http://dx.doi.org/10.4314/ejhs.v29i4.13 


\section{DISCUSSION}

The study revealed that the geographical distribution of child diarrhea was not random in Tanzania. It also showed that socio-demographic factors, mother's age in years, current age of the child, and wealth index were associated with children's diarrhea in Tanzania. Thus, considering the identified hotspot areas and associated factors with childhood diarrhea in the country is highly recommended in striving to design an effective and efficient childhood diarrheal disease intervention strategy.

The results of the recent Demographic Health Survey of Tanzania confirm that diarrhea in children of under five years old remains a public health problem in the country. The national prevalence of childhood diarrhea $(12.1 \%)$ is somewhat lower than the previous survey conducted in $2010(15 \%)$ (20). There was a significant variation in the prevalence of diarrhea in children between different regions and place of residence. Areas of high prevalence were concentrated in Kigoma, Rukwa, Mtwara and Mara Regions. Since diarrhea in children is affected by multiple factors, the major contributing factors to diarrhea in children in different regions found in this study might be different. Epidemiological evidence shows that climatic factors, environmental and behavioral factors, and socio-demographic and economic factors contribute to the occurrence of diarrhea in children (21-23). Moreover, systematic studies revealed that diarrheal diseases are widespread in areas with water scarcity, unsafe drinking water supply, poor hygiene, and lack of sanitation (23, 24). A literature review conducted in Tanzania on sanitation and drinking water coverage showed that there is regional variation with improved drinking water supply and sanitation coverage in the country (25).

The scan spatial statistical analysis also confirmed non-random distribution of diarrhea in children in Tanzania. The most likely cluster was located in the Kusini Pemba Region in the Zanzibar Island, and the three secondary clusters of child diarrhea were located in Kigoma, Rukwa and Mtwara Regions, which support the descriptive results with high prevalence of diarrhea in children. The identified clusters in the study are closely related to specific geographical areas (regions) that share similar geographical parameters, such as altitude and weather conditions, and economic characteristics, improved sanitation and drinking water coverage, which may account for high occurrence of diarrhea directly or indirectly. The aim of spatial statistical analysis is to identify areas with high numbers of cases which in turn help to find evidence of risk factors on which prevention and control activities can be focused, and the identified clusters should be given priority for childhood prevention and control interventions (26).

Age of the child was significantly associated with child diarrhea in this study, which is similar with the findings of other studies conducted elsewhere $(22,27,28)$. The low risk of diarrhea during the age 0-5 months may be due to exclusive breastfeeding and less exposure of children to contaminated agents since most children do not usually start complementary feeding before six months. Children between the ages of 6-11 months had the highest risk of diarrhea compared to 48-59 months. The possible reason for having the highest risk among this age group could be due to crawling on the ground or walking since children usually start at this age which may increase the chance of getting and contacting with filth materials that may expose to pathogenic microorganisms (27). Moreover, the complementary feeding practices usually start after six months which may also increase the occurrence of diarrhea diseases if the food handling and preparation could not be done in a hygienic manner. There is also evidence that complementary feeding increases the risk of diarrhea as a result of cross contamination in this age group (28). The possible reason for decreasing diarrhea subsequently after 6-11 months may be due to development of immunity to pathogens after repeated exposure (28).

In this study, children whose mothers were older were less likely to have child diarrhea compared to those from young mothers, which is consistent with other studies conducted elsewhere

DOI: http://dx.doi.org/10.4314/ejhs.v29i4.13 
(29-31). On the other hand, other studies did not show significant associations between mother's ages and diarrheal disease occurrence among under five children $(21,32)$. The possible explanation could be the difference on knowledge related to prevent and manage diarrhea due to experiences and exposure of information. Those older mothers have a chance to receive more information about diarrhea from health professional or their relatives than younger mothers.

This study also revealed that children from households with higher wealth status had less protective effect on diarrhea. The possible reason could be the nature of the rural life in which the poorest families have limited capacity to dispose of their waste properly compared to the urban. Likewise, the living standard of households with better economic status might be better overall hygienic practice of the household and take care of their children which could reduce the risk of exposure to fecal pathogens compared to poor families. Evidence showed that household socioeconomic status was one of the factors that determine the practice of essential hygiene behaviors (33). Mothers/caregivers in the higher wealth index categories may have been able to afford a cleaner environment for their children, which is contrary to the finding of this study.

This study found that households with improved drinking water and sanitation did not show association with diarrhea. Studies show inconsistent findings on the benefits of improved water and sanitation on diarrhea reduction. Some studies have found that diarrhea was associated with type of drinking water source $(21,34,35)$ while some did not find any association. The systematic review by Clasen in 2015 concluded that there was insufficient evidence to know if source-based improvements of water such as protected wells, communal tap stands, and chlorination/filtration of community sources consistently reduce diarrhea (34). Evidence also shows that improved drinking water may or may not provide microbiologically safe water, or that safe water from these sources becomes contaminated with fecal pathogens during collection, transport and storage in the household (36). WHO also noted that the water that is available at household level is often not safe, sufficiently affordable or available in adequate quantities to meet basic health needs. There was recommendation that indicator for access to water at household level should be revised based on public health benefits (36), and the current indicator used for measuring water access at household level under sustainable goal development is safely managed water which includes drinking water should be located on premises, available when needed and free from faecal and priority chemical contamination.

Improved sanitation was not associated with child diarrhea in this study. The possible justification could be that availability of a latrine does not ensure consistent and proper latrine utilization (33). In addition, studies indicated that sanitation improvements alone have little impact on transmission pathways including water quality or hand, food, toy, surface or soil contamination (37), and improved sanitation alone can be insufficient to reduce pathogen exposure (38) or diarrhea rates (39).

The strength of this study is analyzing such national based cross-sectional survey data using different statistical methods which helps investigating patterns of childhood diarrhea in the country. Thus, it is relevant to health intervention programs in the region where longitudinal and clinical data are limited.

This study has limitations. The reported diarrhea prevalence depends on the ability of the respondents to correctly ascertain the definition of diarrhea and recall bias that occurred two weeks prior to the survey is the limitation of the study. The cross-sectional nature of the study design does not establish cause and effect relationship between exposure and outcome variables.

In conclusion, child diarrhea is not random in Tanzania. Statistically significant hotspot clusters of cases of diarrhea were concentrated in the northern and northwestern parts of the country. The study also revealed that mother's age in years, current children age, and wealth index were significantly associated with diarrhea among under 5 children. Interventions aimed at preventing child diarrhea should focus on the identified hotspot areas. The identified areas will also allow researchers to generate a hypothesis as

DOI: http://dx.doi.org/10.4314/ejhs.v29i4.13 
to the contextual environmental or socioeconomic factors that might influence the distribution of child diarrhea. Education to prevent child diarrhea to the mothers/caretakers is also crucial.

\section{REFERENCES}

1. WHO/UNICEF. WHO and Maternal and Child Epidemiology Estimation Group (MCEE) estimates 2015. Accessed on [https://data.unicef.org/topic/childhealth/diarrhoeal-disease/] 2015.

2. WHO. Diarrhoeal disease. Factshhet update may 2017. Access on [http://www.who.int/mediacentre/factsheets/fs33 0/en/]. 2017.

3. Walker CL, Rudan I, Liu L, Nair H, Theodoratou E, Bhutta ZA, et al. Global burden of childhood pneumonia and diarrhoea. Lancet (London, England). 2013;381(9875):1405-16.

4. Black RE, Cousens S, Johnson HL, Lawn JE, Rudan I, Bassani DG, et al. Global, regional, and national causes of child mortality in 2008: a systematic analysis. Lancet (London, England). 2010;375(9730):1969-87.

5. Ministry of Health and Social Welfare. Health Management Information System Report of 2009. Dar es Salaam, Tanzania: Ministry of Health and Social Welfare. 2009.

6. Ministry of Health and Social Welfare. Health management information System report of 2010. Dar es Salaam, Tanzania: Ministry of Health and Social Welfare. 2010.

7. Mashoto KO, Malebo HM, Msisiri E, Peter E. Prevalence, one week incidence and knowledge on causes of diarrhea: household survey of under-fives and adults in Mkuranga district, Tanzania. BMC public health. 2014;14:985.

8. Temu A, Kamugisha E, Mwizamholya DL, Hokororo A, Seni J, Mshana SE. Prevalence and factors associated with Group A rotavirus infection among children with acute diarrhea in Mwanza, Tanzania. The Journal of Infection in Developing Countries. 2011;6(06):508-15.

9. Oketcho R, Karimuribo ED, Nyaruhucha CN, Taybali S. Epidemiological factors in admissions for diarrhoea in 6-60-month-old children admitted to Morogoro Regional Hospital, Tanzania. South African Journal of Child Health. 2012;6(3):81-4.
10. Ministry of Health/National Bureau of Statistics. Tanzania Demographic and Health Survey and Malaria Indicator Survey (TDHS-MIS) 201516. Dar es Salaam, Tanzania, and Rockville, Maryland, USA: MoHCDGEC, MoH, NBS, OCGS, and ICF. . 2016.

11. Agrest A. Categorical Data Analysis (2nd ed.). New York: John Wiley and Sons. 2002.

12. Bennett S, Woods T, Liyanage WM, Smith DL. A simplified general method for clustersampling surveys of health in developing countries. World Health Stat. 1991;44(3):98.

13. Faes C, Hens N, Aerts M, Shkedy Z, Geys H, Mintiens K, et al. Estimating herd-specific force of infection by using random-effects models for clustered binary data and monotone fractional polynomials. Appl Statist. 2006;55(5):595-613.

14. Molenberghs G, Verbeke G. Models for Discrete Longitudinal Data. New York: Springer. 2005.

15. Briggs DJ, Elliott P. The use of geographical information systems in studies on environment and health. World Health Stat Q. 1995;48(2):85.

16. Elliott P, Wartenberg D. Spatial epidemiology: current approaches and future challenges. Environ Health Perspect. 2004;112(9):9981006.

17. ICF International. Demographic and Health Survey Sampling and Household Listing Manual. Calverton: ICF International. 2012.

18. Verbeke G, Molenberghs G. Generalized Linear Mixed Models-Overview. 2013.

19. Kulldorff M. SaTScan User Guide for version 9.3. March 2014 ed. 2014.

20. Macro II. Tanzania demographic and health survey 2010. 2011.

21. Dessalegn M, Kumie A, Tefera W. Predictors of under five childhood Diarrrhea: Mecha district, West Gojjam, Ethiopia. Ethiopian Journal Of Health development. 2011;25(3):192-200.

22. Sinmegn Mihrete T, Asres Alemie G, Shimeka Teferra A. Determinants of childhood diarrhea among underfive children in Benishangul Gumuz Regional State, North West Ethiopia. BMC pediatrics. 2014;14:102.

23. Prüss-Üstün A CC. Preventing disease through health environments Towards an estimate of the environmental burden of disease. Geneva: World Health Organization; 2006. 2006.

24. Lamberti LM, Fischer Walker CL, Black RE. Systematic review of diarrhea duration and

DOI: http://dx.doi.org/10.4314/ejhs.v29i4.13 
severity in children and adults in low- and middle-income countries. BMC public health. 2012;12:276.

25. Thomas J, Holbro N, Young D. A review of sanitation and hygiene in Tanzania. DFID, London. 2013.

26. Odoi A, Martin SW, Michel P, Middleton D, Holt $\mathrm{J}$, Wilson $\mathrm{J}$. Investigation of clusters of giardiasis using GIS and a spatial scan statistic. Int J Health Geogr. 2004;3(1):11.

27. Pickering AJ, Julian TR, Marks SJ, Mattioli MC, Boehm AB, Schwab KJ, et al. Fecal contamination and diarrheal pathogens on surfaces and in soils among Tanzanian households with and without improved sanitation. Environmental science \& technology. 2012;46(11):5736-43.

28. Motarjemi Y, Kaferstein F, Moy G, Quevedo F. Contaminated weaning food: a major risk factor for diarrhoea and associated malnutrition. Bulletin of the World Health Organization. 1993;71(1):79-92.

29. Yassin K. Morbidity and risk factors of diarrheal diseases among under-five children in rural Upper Egypt. Journal of tropical pediatrics. 2000;46(5):282-7.

30. Ghasemi AA, Talebian A, Masoudi Alavi N, Moosavi G. Knowledge of mothers in management of diarrhea in under-five children, in kashan, iran. Nurs midwifery stud. 2013;1(3):158-62.

31. Boadi KO, Kuitunen M. Childhood diarrheal morbidity in the Accra Metropolitan Area, Ghana: socio-economic, environmental and behavioral risk determinants. World Health \& Population. 2005.

32. Shah SM, Yousafzai M, Lakhani NB, Chotani RA, Nowshad G. Prevalence and correlates of diarrhea. The Indian Journal of Pediatrics. 2003;70(3):207-11.
33. Routray P, Schmidt WP, Boisson S, Clasen T, Jenkins MW. Socio-cultural and behavioural factors constraining latrine adoption in rural coastal Odisha: an exploratory qualitative study. BMC public health. 2015;15:880.

34. Clasen TF, Alexander KT, Sinclair D, Boisson $\mathrm{S}$, Peletz R, Chang $\mathrm{HH}$, et al. Interventions to improve water quality for preventing diarrhoea. Cochrane Database Syst Rev. 2015;10:CD004794.

35. 35. Mengistie B, Berhane $\mathrm{Y}$, Worku A. Prevalence of diarrhea and associated risk factors among children under-five years of age in Eastern Ethiopia: A cross-sectional study. Open Journal of Preventive Medicine. 2013;3(7):446-53.

36. Shaheed A, Orgill J, Montgomery MA, Jeuland MA, Brown J. Why "improved" water sources are not always safe. Bulletin of the World Health Organization. 2014;92(4):283-9.

37. Sclar GD, Penakalapati G, Amato HK, Garn JV, Alexander K, Freeman MC, et al. Assessing the impact of sanitation on indicators of fecal exposure along principal transmission pathways: A systematic review. International journal of hygiene and environmental health. 2016;219(8):709-23.

38. Odagiri M, Schriewer A, Daniels ME, Wuertz S, Smith WA, Clasen T, et al. Human fecal and pathogen exposure pathways in rural Indian villages and the effect of increased latrine coverage. Water research. 2016;100:232-44.

39. Clasen T, Boisson S, Routray P, Torondel B, Bell M, Cumming O, et al. Effectiveness of a rural sanitation programme on diarrhoea, soiltransmitted helminth infection, and child malnutrition in Odisha, India: a clusterrandomised trial. The Lancet Global health. 2014;2(11):e645-53. 